\title{
The influence of small-scale variations in isoprene concentrations on atmospheric chemistry over a tropical rainforest
}

\author{
T. A. M. Pugh ${ }^{1}$, A. R. MacKenzie ${ }^{1}$, B. Langford ${ }^{1, *}$, E. Nemitz ${ }^{2}$, P. K. Misztal ${ }^{2,3, * *}$, and C. N. Hewitt ${ }^{1}$ \\ ${ }^{1}$ Lancaster Environment Centre, Lancaster University, Lancaster, UK \\ ${ }^{2}$ Centre for Ecology and Hydrology, Edinburgh, UK \\ ${ }^{3}$ School of Chemistry, University of Edinburgh, Edinburgh, UK \\ * now at: Centre for Ecology and Hydrology, Edinburgh, UK \\ ** now at: Department of Environmental Science, Policy, and Management, University of California, Berkeley, CA, USA
}

Received: 16 April 2010 - Published in Atmos. Chem. Phys. Discuss.: 30 July 2010

Revised: 12 April 2011 - Accepted: 29 April 2011 - Published: 4 May 2011

\begin{abstract}
Biogenic volatile organic compounds (BVOCs) such as isoprene constitute a large proportion of the global atmospheric oxidant sink. Their reactions in the atmosphere contribute to processes such as ozone production and secondary organic aerosol formation. However, over the tropical rainforest, where $50 \%$ of the global emissions of BVOCs are believed to occur, atmospheric chemistry models have been unable to simulate concurrently the measured daytime concentration of isoprene and that of its principal oxidant, hydroxyl $(\mathrm{OH})$. One reason for this model-measurement discrepancy may be incomplete mixing of isoprene within the convective boundary layer, leading to patchiness or segregation in isoprene and $\mathrm{OH}$ mixing ratios and average concentrations that appear to be incompatible with each other. One way of capturing this effect in models of atmospheric chemistry is to use a reduced effective rate constant for their reaction. Recent studies comparing atmospheric chemistry global/box models with field measurements have suggested that this effective rate reduction may be as large as $50 \%$; which is at the upper limit of that calculated using large eddy simulation models. To date there has only been one field campaign worldwide that has reported co-located measurements of isoprene and $\mathrm{OH}$ at the necessary temporal resolution to calculate the segregation of these compounds. However many campaigns have recorded sufficiently high resolution isoprene measurements to capture the small-scale fluctuations in its concentration. Assuming uniform distributions
\end{abstract}

Correspondence to: T. A. M. Pugh

(t.pugh@lancs.ac.uk) of other $\mathrm{OH}$ production and loss processes, we use a box model of atmospheric chemistry, constrained by the spectrum of isoprene concentrations measured, as a virtual instrument, to estimate the variability in $\mathrm{OH}$ at a point and hence, to estimate the segregation intensity of isoprene and $\mathrm{OH}$ from high-frequency isoprene time series. The method successfully reproduces the only directly observed segregation, using measurements made in a deciduous forest in Germany. The effective rate constant reduction for the reaction of isoprene and $\mathrm{OH}$ over a South-East Asian rainforest is calculated to be typically $<15 \%$. Although there are many unconstrained uncertainties, the likely nature of those processes suggests that this value represents an upper limit. The estimate is not sensitive to heterogeneities in NO at this remote site, unless they are correlated with those of isoprene, or to OH-recycling schemes in the isoprene oxidation mechanism, unless the recycling happens in the first reaction step. Segregation alone is therefore unlikely to be the sole cause of model-measurement discrepancies for isoprene and $\mathrm{OH}$ above a rainforest.

\section{Introduction}

The volatile organic compound (VOC) isoprene $\left(\mathrm{C}_{5} \mathrm{H}_{8}\right)$ is believed to account for $44 \%$ of global biogenic emissions of VOCs (Guenther et al., 1995). The very high reactivity of isoprene with respect to common tropospheric oxidants makes its impact on tropospheric chemistry, particularly in the planetary boundary layer (BL), very significant. Modelling studies have suggested that areas in which high

Published by Copernicus Publications on behalf of the European Geosciences Union. 
emissions of isoprene occur, for instance the tropical rainforest or mid-latitude deciduous forests, should see suppression of hydroxyl radical $(\mathrm{OH})$ concentrations in the boundary layer (Wang et al., 1998; Lawrence et al., 1999; Granier et al., 2000; Poisson et al., 2000; Lelieveld et al., 2002; von Kuhlmann et al., 2004; Jöckel et al., 2006). This is of great consequence, as the $\mathrm{OH}$ radical is the primary sink for a large range of chemicals emitted into the atmosphere, including the greenhouse gas methane.

Over the past decade several measurement studies have noted much higher concentrations of $\mathrm{OH}$ in areas of high isoprene concentration than has been predicted by models of atmospheric chemistry (Tan et al., 2001; Carslaw et al., 2001; Ren et al., 2008; Lelieveld et al., 2008; Martinez et al., 2010; Hofzumahaus et al., 2009; Pugh et al., 2010). It has been proposed that the sources of $\mathrm{OH}$ in these high isoprene environments may be underestimated and several suggestions for additional methods of $\mathrm{OH}$ formation have been put forward (Lelieveld et al., 2008; Hofzumahaus et al., 2009; Peeters et al., 2009; Whalley et al., 2011). Whilst these methods are successful in increasing modelled $[\mathrm{OH}]^{1}$ in these regions to within the bounds of the measurements, these increases in $[\mathrm{OH}]$ lead to faster oxidation, and hence lower concentrations, of isoprene. Butler et al. (2008) and Pugh et al. (2010) have shown that the increases in isoprene emission required to rectify this isoprene underestimation exceed the available isoprene flux in these regions and furthermore lead to a resuppression of $[\mathrm{OH}]$.

Butler et al. (2008) hypothesised that the reason for the discrepancy between modelled and measured isoprene and $\mathrm{OH}$ may lie with the rate of reaction between isoprene and $\mathrm{OH}$ used in chemical models. The rate of change of isoprene concentration with respect to its reaction with $\mathrm{OH}$ can be represented by

$$
\frac{\partial\left\langle\mathrm{C}_{5} \mathrm{H}_{8}\right\rangle}{\partial t}=-k_{\mathrm{C}_{5} \mathrm{H}_{8}, \mathrm{OH}}\left(\langle\mathrm{OH}\rangle\left\langle\mathrm{C}_{5} \mathrm{H}_{8}\right\rangle+\left\langle\mathrm{OH}^{\prime} \mathrm{C}_{5} \mathrm{H}_{8}{ }^{\prime}\right\rangle\right),
$$

where the angle brackets represent volume averages, and the primes represent deviations from the mean concentration. In a typical atmospheric chemistry model, concentrations are assumed to be uniform within a box and the term containing the primes is neglected. However studies with large eddy simulation (LES) models have shown that the contribution of the prime term can be substantial for atmospheric reactions where the timescale of the chemical reaction is of the same order as the mixing timescale (e.g. Schumann, 1989; Sykes et al., 1994; Krol et al., 2000; Patton et al., 2001; Vinuesa and Vilà Guerau de Arellano, 2003). Using an intensity of segregation metric, $S$ (e.g. Krol et al., 2000), where

$S_{\mathrm{C}_{5} \mathrm{H}_{8}, \mathrm{OH}}=\frac{\left\langle\mathrm{OH}^{\prime} \mathrm{C}_{5} \mathrm{H}_{8}{ }^{\prime}\right\rangle}{\langle\mathrm{OH}\rangle\left\langle\mathrm{C}_{5} \mathrm{H}_{8}\right\rangle}$,

\footnotetext{
${ }^{1}$ Square brackets are used herein to indicate concentrations where no averaging has been applied or is specified.
}

this effect can be represented by a modified reaction rate coefficient, $k_{\text {eff }}$,

$k_{\text {eff }}=k_{\mathrm{C}_{5} \mathrm{H}_{8}, \mathrm{OH}}\left(1+S_{\mathrm{C}_{5} \mathrm{H}_{8}, \mathrm{OH}}\right)$.

A negative value of $S$ implies that the two reactants are spatially anti-correlated, whereas a positive value implies a positive correlation, and $S=0$ indicates a random distribution of anomalies or a homogeneous distribution. In their idealised LES modelling study, Krol et al. (2000) found that, under conditions of heterogeneous emissions, $S_{\mathrm{VOC}, \mathrm{OH}}=-0.294$ was simulated for a reaction between a VOC and $\mathrm{OH}$. In their study, the effective reaction rate of VOC and $\mathrm{OH}$ was $25 \%$ of that of the $\mathrm{C}_{5} \mathrm{H}_{8}+\mathrm{OH}$ reaction rate at 298K (IUPAC, 2009). Similarly, in the development of a parameterisation for segregation intensity, Vinuesa and Vilà Guerau de Arellano (2005) suggest $S_{\mathrm{VOC}, \mathrm{OH}}=-0.405$, where the reactants react at a rate similar to that of the $\mathrm{C}_{5} \mathrm{H}_{8}$ $+\mathrm{OH}$ reaction rate at $298 \mathrm{~K}$. Such segregation can occur for $\mathrm{C}_{5} \mathrm{H}_{8}$ and $\mathrm{OH}$ because, due to the extremely rapid reaction rate between the two compounds, $[\mathrm{OH}]$ rapidly approaches a steady state between its loss due to isoprene and its various production processes, on a timescale of the order of one second (Appendix A). Therefore if isoprene is not uniformly distributed throughout the model box, $\mathrm{OH}$ concentrations will also vary, with the lowest $\mathrm{OH}$ concentrations colocated with the highest isoprene concentrations, assuming other $\mathrm{OH}$ sinks are uniform. Isoprene itself has a chemical lifetime in the boundary layer which is similar to typical turbulent mixing timescales (e.g. Butler et al., 2008; Pugh et al., 2010), while its flux into the BL is subject to heterogeneities likely influenced by the coupling of the canopy to the turbulent BL (e.g. Patton et al., 2001), the local dispersion of isoprene emitting plants, and variations in light and temperature. Therefore it is highly probable that heterogeneities of isoprene concentration within the boundary layer will occur.

Based upon comparisons between measurements over the Amazonian rainforest and simulations using a global chemistry model, Butler et al. (2008) found $S_{\mathrm{C}_{5} \mathrm{H}_{8}, \mathrm{OH}}=-0.6$ was required to reconcile measured and modelled concentrations if the standard IUPAC rate constant for $\mathrm{C}_{5} \mathrm{H}_{8}+\mathrm{OH}$ is used. ${ }^{2}$ In a similar experiment, but using a box model and measurements over a south-east Asian rainforest as part of the Oxidant Particle and Photochemical Processes (OP3) campaign, Pugh et al. (2010) required $S_{\mathrm{C}_{5} \mathrm{H}_{8}, \mathrm{OH}}=-0.5$ to attain a good agreement between measurements and their model. Considering that there is also a $20 \%$ uncertainty in the IUPAC rate constant, such values do not appear unreasonable in the context of the LES studies above.

Direct atmospheric measurements of segregation require co-located measurements of both species at a temporal resolution fast enough to resolve the smallest relevant spatial

\footnotetext{
${ }^{2}$ Butler et al. (2008) report a rate constant reduction of $50 \%$ below the lower uncertainty bound of the $\mathrm{C}_{5} \mathrm{H}_{8}+\mathrm{OH}$ rate constant of $20 \%$, as specified by IUPAC, leading to an overall reduction of $60 \%$.
} 
scales. Butler et al. (2008) calculated $S_{\mathrm{C}_{5} \mathrm{H}_{8}, \mathrm{OH}}=-0.13$ using aircraft measurements over the Guyanas; however at the speed of the aircraft the temporal resolution of the measurements resulted in a measurement scale of the order of several hundred metres. Hence smaller scale segregation would have been missed. To date only one study has measured $S_{\mathrm{C}_{5} \mathrm{H}_{8}, \mathrm{OH}}$ at a ground-based station, with Dlugi et al. (2010) finding values of $S_{\mathrm{C}_{5} \mathrm{H}_{8}, \mathrm{OH}}$ as negative as -0.15 over a deciduous forest in Germany, although their study is limited to a single day of measurements.

During OP3, high-temporal resolution measurements of $[\mathrm{OH}]$ co-located with those of isoprene were not available. Here we use high temporal resolution isoprene concentration measurements (Langford et al., 2010) made over a southeast Asian rainforest as part of the OP3 campaign (Hewitt et al., 2010), in conjunction with a box model of atmospheric chemistry, which is used as a virtual instrument to estimate $[\mathrm{OH}]$, and hence estimate the intensity of segregation of isoprene and $\mathrm{OH}$ in this region. First the measurements are described, followed by a description of the modelling approach used. Results are then presented and discussed.

\section{Measurements}

Measurements of isoprene concentration were made using a proton-transfer reaction mass spectrometer (PTR-MS) during April/May 2008 at the Bukit Atur Global Atmosphere Watch station $\left(4^{\circ} 58^{\prime} 59^{\prime \prime} \mathrm{N}, 117^{\circ} 50^{\prime} 39^{\prime \prime} \mathrm{E}\right)$. The station is located at an altitude of $437 \mathrm{~m}$ a.m.s.l., on a small hill approximately $260 \mathrm{~m}$ above the valley floor and the surrounded by primary and secondary rainforest (Hewitt et al., 2010), with a typical canopy height of $25 \mathrm{~m}$ (N. Chappell, Lancaster University, pers. comm.). On top of the hill stands a $100 \mathrm{~m}$ tall, open-pylon type tower which was instrumented with a sonic anemometer at $75 \mathrm{~m}$ and a low pressure $(60 \mathrm{kPa})$ PTFE gas inlet tube (length: $85 \mathrm{~m}$; OD $\frac{1^{\prime \prime}}{2}$ ). For the purpose of turbulence calculations, these measurements are considered to be $\sim 125 \mathrm{~m}$ above the forest canopy, taking into account that the measurement tower is sited on a hill (Helfter et al., 2010; Langford et al., 2010).

The PTR-MS was housed in an air-conditioned laboratory at the base of the tower and sub-sampled from the inlet at a rate of $0.31 \mathrm{~min}^{-1}$, via a short length of PTFE tubing $\left(\frac{1}{8}{ }^{\prime \prime}\right.$ OD). The flow in the main inlet line was turbulent, minimising the dampening of the VOC signal (Spirig et al., 2005). Individual compounds were sampled, iteratively, providing for each compound a disjunct time-series with a value every $\sim 7 \mathrm{~s}$, that is measured with an integration time of $0.5 \mathrm{~s}$ and an overall instrument response time of $1 \mathrm{~s}$. These data are available for a continuous $25 \mathrm{~min}$ period out of every $30 \mathrm{~min}$. The remaining $5 \mathrm{~min}$ were devoted to calibration techniques and scans of the mass spectrum. A complete description of these measurements and set-up can be found in Langford et al. (2010).

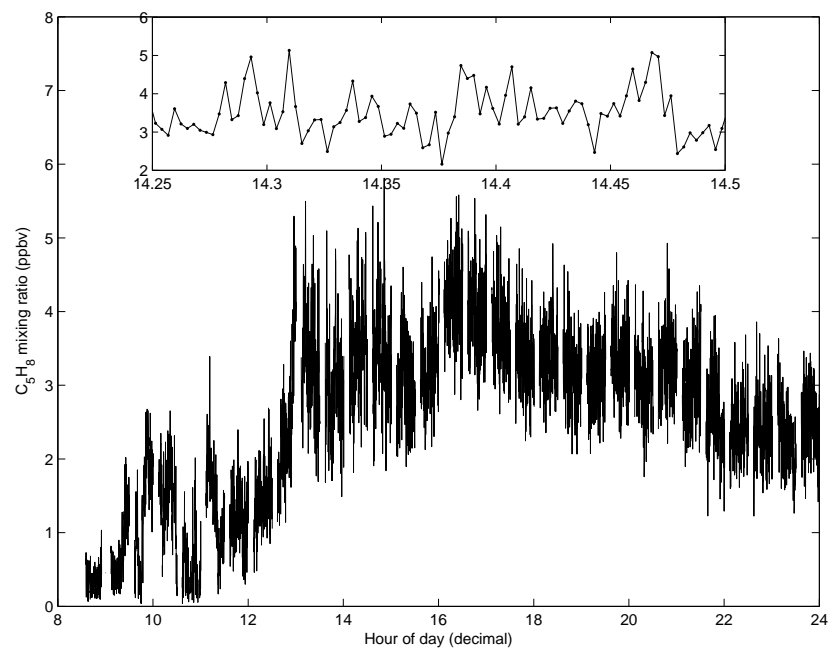

Fig. 1. Isoprene concentration data measured by PTR-MS for 26/04/08 showing 1 data point every $10 \mathrm{~s}$. The inset shows a $15 \mathrm{~min}$ extract (note hours given as decimal fraction) indicating the short timescale over which large variations can occur.

Figure 1 shows an example of isoprene concentration measurements for a single day (26 April 2008). Although the diurnal cycle in the measurements is clear, substantial variation is seen around the mean. The inset indicates that these variations in isoprene concentration often have a magnitude similar to the mean isoprene concentration. These fluctuations occur on a timescale of less than one minute. If they are characteristic of the real atmosphere they indicate large inhomogeneities in the isoprene distribution on length scales of $<180 \mathrm{~m}$, considering a wind speed $<3 \mathrm{~ms}^{-1}$.

To test whether these concentration fluctuations are a real feature of the atmosphere, or are due to instrument noise, a statistical analysis was carried out. Hayward et al. (2002) showed that the instrument noise signal for the PTR-MS can be well-approximated by a Gaussian distribution. They show that the standard deviation of noise varies with the signal strength and can be reliably predicted by the noise statistic $(N S)$ :

$N S=\frac{\bar{c}}{\sqrt{\bar{c} \times \delta}}$,

where $\bar{c}$ is the mean signal recorded by the PTR-MS in units of ion counts per second, i.e. the number of instances in which that compound is registered at the detector each second. This is later converted into a mixing ratio as described in Langford et al. (2010). The dwell time, $\delta$, is the time spent scanning for each compound. For more information on these terms the reader is referred to Hayward et al. (2002). As NS is analogous to standard deviation, if the rapid fluctuations in the measured isoprene concentration are purely due to instrument noise, $4.4 \%$ of recorded values should fall outside $\pm 2 N S$ (Hayward et al., 2002). 


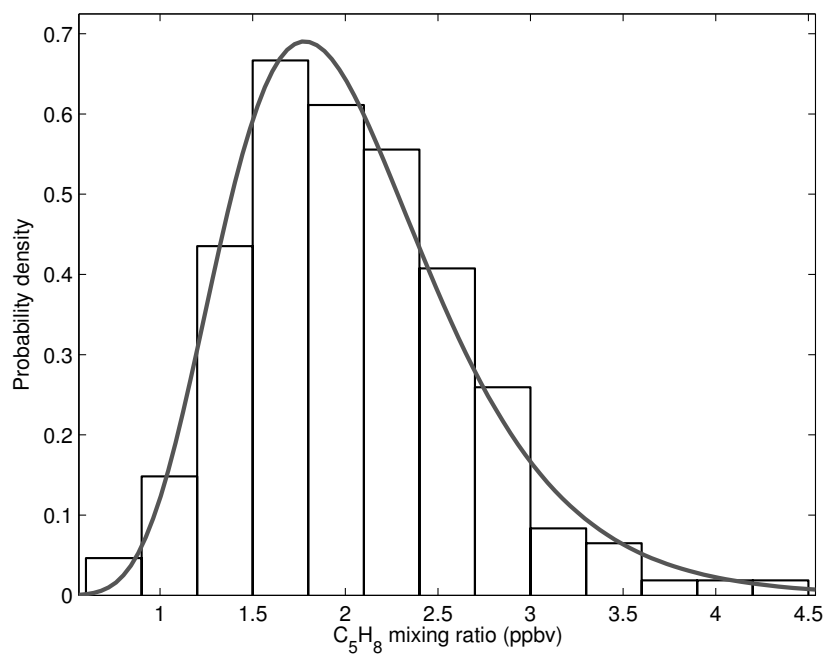

Fig. 2. Histogram showing distribution of isoprene concentrations between 11:00 and 12:00 LT on 30 April 2008. The line shows the probability density function for a log-normal distribution.

Calculating NS for the isoprene concentration data collected between 10:00-18:00 LT on 26 April 2008, using a 10 min running mean to calculate $\bar{c}$, reveals that $10.5 \%$ of these data lie outside $\pm 2 N S$ (3000 datapoints). This indicates that instrument noise is highly unlikely to be responsible for all of the variation measured and shows that variations in isoprene concentration of this magnitude were present in the atmosphere during OP3. In addition, the distribution is close to log-normal (Fig. 2), which is representative of the statistical distribution of atmospheric concentrations, rather than random ion noise, which follows a Poisson distribution. Although it is not possible to differentiate between the smaller variations and instrument noise, it is the large fluctuations that will be of most importance in the analysis that follows.

\section{Modelling}

\subsection{Approach}

If a snapshot of the boundary layer is taken in time, a range of isoprene concentrations will be revealed in the spatial domain. Because isoprene is the dominant $\mathrm{OH}$ sink in the tropical forest environment, the variability in isoprene concentration induces variability in $\mathrm{OH}$ concentration. If isoprene is well mixed within the boundary layer, the variations in isoprene (and thus $\mathrm{OH}$ ) concentrations will be small, and average concentrations are sufficient for calculations of chemistry. However, a boundary layer in which isoprene is not well mixed will display a large standard deviation of concentrations for isoprene, which will induce a large variation in $\mathrm{OH}$ concentrations, resulting in a strong covariance between isoprene and $\mathrm{OH}$. Ideally co-located measurements would be used to measure this covariance. However, here we argue that the $\mathrm{OH}$ time series that would have resulted from a suitable $\mathrm{OH}$ measurement co-located with the isoprene measurement, can be estimated purely on the basis of chemistry. For most species such a procedure would not be possible. However, two key simplifying aspects of our system are (a) that $\mathrm{OH}$ is produced in-situ everywhere throughout the boundary layer and, (b) due to its short lifetime, $\mathrm{OH}$ is always in steadystate with its chemical sources and sinks. This means that the $\mathrm{OH}$ concentration at a place and time is independent of the history of the air at that place. The $\mathrm{OH}$ concentration is therefore a function of the instantaneous value of chemical production, $P$, its major chemical sink in the rainforest environment, isoprene, and other chemical sinks, $O L$ :

$[\mathrm{OH}]=f\left(\left[\mathrm{C}_{5} \mathrm{H}_{8}\right], P, O L\right)$

and there are no advective terms to be considered. Our knowledge of (and uncertainty in) the chemical source and sink terms for $\mathrm{OH}$ is embodied in chemical mechanisms. It follows that our best theoretical estimate of $\mathrm{OH}$ mixing ratios will come from integrating chemical mechanisms to steadystate, given adequate empirical data on the mixing ratios of longer-lived compounds that dominate $P$ and $O L$.

The ratio of turbulent timescale to chemical timescale is known as the Damköhler ratio $\left(D_{a}\right)$. Turbulence and chemistry interact when $D_{a}$ is of the order of 1 . For $D_{\mathrm{a}} \ll 1$ turbulence controls the variability and for $D_{a} \gg 1$ chemistry dominates (Vilà Guerau de Arellano et al., 1995). The OH lifetime, with respect to isoprene, at a typical mixing ratio of $2 \mathrm{ppbv}$, is $0.22 \mathrm{~s}$ at $298 \mathrm{~K}$. The median diurnal profile of vertical velocity during the OP3 measurement period considered in this paper peaks at approximately $0.2 \mathrm{~m} \mathrm{~s}^{-1}$. Therefore the transport distance of $\mathrm{OH}$ during its lifetime is less than $0.05 \mathrm{~m}$, cf. the scale of a few metres we assume for our measured air parcels (based upon a typical windspeed of a few metres per second and Taylor's frozen turbulence hypothesis, Powell and Elderkin, 1974), and therefore $D_{a} \gg 1$. As a result any covariance of isoprene and $\mathrm{OH}$ must be due to the $\mathrm{OH}$ concentration adjusting chemically to a change in the isoprene concentration, demonstrating requirement (b). Dlugi et al. (2010) also found transport of $\mathrm{OH}$ to be negligible based on both the same logic, and on measurements of $\mathrm{OH}$ fluxes.

In order to fully capture $S_{\mathrm{C}_{5} \mathrm{H}_{8} \text {, OH }}$ isoprene must be measured sufficiently fast to resolve the fastest fluctuations that contribute to the covariance with $\mathrm{OH}$. The isoprene timeseries represents $1 \mathrm{~s}$ average values approximately every $10 \mathrm{~s}$. Assuming that Taylor's frozen turbulence hypothesis (Powell and Elderkin, 1974) holds for reactive compounds, a measured isoprene concentration time-series with a temporal resolution of $1 \mathrm{~s}$ is transformed into a length scale, or spatial resolution, of $4 \mathrm{~m}$ or less, when measured wind speeds are $4 \mathrm{~m} \mathrm{~s}^{-1}$ or less. Little is known about the frequency distribution (and thus the length-scale) of the covariance between $\mathrm{OH}$ and isoprene and other chemical systems. In a study 
utilising a LES model, Vinuesa and Porte-Agel (2008) found that the sub-grid scale mixing term could be neglected when a horizontal resolution of $\sim 50 \mathrm{~m}$ or less was used. In our study, at the high effective measurement height of $125 \mathrm{~m}$, $>90 \%$ of the variance and flux were estimated to be carried in eddies slower than $1 \mathrm{~Hz}$ (Helfter et al., 2010; Langford et al., 2010) and it is likely that the high-frequency contribution to the $\mathrm{OH}$-isoprene covariance is even smaller because of the damping induced by the fast chemistry. Thus the isoprene measurement is thought to be taken at a sufficiently high temporal resolution to effectively characterise $S_{\mathrm{C}_{5} \mathrm{H}_{8}, \mathrm{OH}}$.

If, in addition, the air advecting past the measurement point is assumed to contain a range of isoprene concentrations representative of the boundary layer as a whole, then the measurements can be generalised to the whole boundary layer for comparison with results from atmospheric chemistry models. The close agreement found between the average of the isoprene measurements used in this study and aircraft measurements made in the boundary layer (Hewitt et al., 2009) gives confidence that the PTR-MS isoprene measurements used here are representative of the boundary layer as a whole, fufilling this condition.

Because the isoprene measurement is non-continuous, it only provides a good statistical representation of the distribution of $1 \mathrm{~s}$ data points. Some of the information on the temporally organised structure in the variability does get lost. However, as discussed above, the $\mathrm{OH}$ concentration at a place and time is independent of the history of the air at that place. Therefore, given a sufficient time window, $t_{s}$, a representative sample of the population of isoprene concentrations advected past the detector should be obtained, and a histogram can be constructed showing the probability distribution of the measured isoprene concentration (Fig. 2).

By calculating the average sampled isoprene concentration and modelled $\mathrm{OH}$ concentration over $t_{s}$, estimates can be gained for $\left\langle\mathrm{C}_{5} \mathrm{H}_{8}\right\rangle$ and $\langle\mathrm{OH}\rangle$. Hence Eq. (2) can be approximated by,

$S_{\mathrm{C}_{5} \mathrm{H}_{8}, \mathrm{OH}} \approx \frac{\overline{\mathrm{OH}^{\prime} \mathrm{C}_{5} \mathrm{H}_{8}{ }^{\prime}}}{\overline{\mathrm{OH}_{5} \mathrm{H}_{8}}}$,

where the over-bars represent time averages. We are not directly converting a time series measurement into a spatial scale of eddy size (evoking Taylor's frozen turbulence hypothesis). Rather a set of discreet samples recorded in the time domain are used to represent the spatial variation of a population of those samples throughout the boundary layer. An appropriate length for $t_{s}$ is discussed in Sect. 3.2. We note

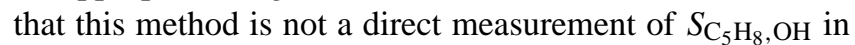
the BL. However, given the complexities of making such a direct measurement, this approximation is of utility.

Because, as explained previously, transport of $\mathrm{OH}$ is negligible, the $\mathrm{OH}$ concentration at a point in space and time can be calculated from all the production and loss terms at that point by expanding Eq. (5),

$[\mathrm{OH}]=\frac{P}{\left(k_{\left.\mathrm{C}_{5} \mathrm{H}_{8}, \mathrm{OH}\left[\mathrm{C}_{5} \mathrm{H}_{8}\right]\right)+\left(k_{O L, \mathrm{OH}}[O L]\right)} .\right.}$

Where $O L$ is the sum of all $\mathrm{OH}$ sinks other than $\mathrm{C}_{5} \mathrm{H}_{8}$, and $P$ is the $\mathrm{OH}$ production rate. Our approximation (discussed further below) is that the species determining $P$ and $O L$ are well-mixed compared to isoprene. Hence, when computing $\mathrm{OH}$ at the point in space and time at which the isoprene measurements are made, we use the instantaneous value of isoprene but volume average values for $P$ and $O L$ derived from the box model. We discuss the implications of our approximations for the calculation of $S_{\mathrm{C}_{5} \mathrm{H}_{8}, \mathrm{OH}}$ in Sect. 4.3 and conclude that our value for the magnitude of $S_{\mathrm{C}_{5} \mathrm{H}_{8}, \mathrm{OH}}$ is likely to be an upper limit.

As $P$ and $O L$ are complicated terms, they are most easily calculated using a numerical chemistry box model constrained to the measured $\left[\mathrm{C}_{5} \mathrm{H}_{8}\right]$. It is emphasised here that the box model is used purely as a convenient tool to carry out chemical mechanism calculations, and not to capture mixing processes. Hence the chemical model acts as a virtual $\mathrm{OH}$ instrument with precisely the temporal and spatial resolution of the isoprene measurements. Note that this method does not produce a continuous $[\mathrm{OH}]$ time-series, but rather a set of $[\mathrm{OH}]$ samples, which correspond to the measured samples of $\left[\mathrm{C}_{5} \mathrm{H}_{8}\right]$ at a given time. If the re-equilibration of $\mathrm{OH}$ concentrations (Appendix A) occurred over a longer time period than the isoprene sampling interval, then the model would not find the new steady-state $[\mathrm{OH}]$ before the next change in $\left[\mathrm{C}_{5} \mathrm{H}_{8}\right]$, and the model generated $[\mathrm{OH}]$ time-series would not be valid, given that no information exist on the isoprene concentration of $9 \mathrm{~s}$ after each $1 \mathrm{~s}$ sample. Appropriate values for $[\overline{\mathrm{OH}}]$ and $\left[\overline{\mathrm{C}_{5} \mathrm{H}_{8}}\right]$ are provided by taking running means over the time window, $t_{s}$. So effectively a running sample of the population is being taken. This avoids unnecessary and arbitary discretisation of the segregation signal and is similar to running mean filtering in the calculation of surface exchange fluxes, i.e. co-variances of concentration with wind components (McMillen, 1988). $\mathrm{OH}^{\prime}$ and $\mathrm{C}_{5} \mathrm{H}_{8}{ }^{\prime}$ are then easily calculated from the time series, and hence $S_{\mathrm{C}_{5} \mathrm{H}_{8}, \mathrm{OH}}$ can be calculated using Eq. (6).

An important consideration are the secondary oxidation products of isoprene, which may be preferentially co-located with high isoprene concentrations, depending on the ratio of the turbulence timescale, $\tau_{t}$, to their chemical lifetime, $\tau_{\mathrm{c}}$. However, the lifetimes of all secondary oxidation products of isoprene which may impact the $\mathrm{OH}$ sink are much greater than the timescale for mixing out of our measured air parcel, which has a length-scale of a few metres $\left(D_{a} \ll 1\right)$. Hence it is assumed that the concentrations of secondary oxidation products of isoprene are not co-variant with those of isoprene, and effectively consistute random noise in the $S_{\mathrm{C}_{5} \mathrm{H}_{8}, \mathrm{OH}}$ signal. Therefore it is better to assume a homogeneous mixture, limiting our conclusions to the segregation of isoprene and $\mathrm{OH}$ 
only. The use of the constrained box model in the manner described above implicitly mixes all species homogeneously across all air samples if those species have a lifetime longer than the sampling period. It is worth noting here that the accuracy of this method is greatly increased if the $\mathrm{OH}$ sink is dominated by isoprene chemistry (as at both sites in Sect. 4), as this reduces potential errors due to a possible poor characterisation of $O L$.

Running a model constrained to measured concentrations is a typical approach for studying chemical processes in the atmosphere and testing model chemical mechanisms using both ground-based (e.g. Carslaw et al., 2001; Emmerson et al., 2005, 2007; Hofzumahaus et al., 2009; Kanaya et al., 2007, 2009) and aircraft-based (e.g. Ren et al., 2008; Kubistin et al., 2010) measurements. However a model has not before been used in this manner as a virtual instrument, for the purposes of calculating segregation. The above listed studies typically use measurements of VOCs, $\mathrm{NO}_{\mathrm{x}}, \mathrm{O}_{3}, \mathrm{CO}$ and other intermediate/long-lived species, as boundary conditions to attempt to calculate radical concentrations. All these studies utilise measurements with a temporal resolution of greater than $1 \mathrm{~min}$ for the aircraft based measurements and in the region 5-15 min for the ground based measurements. They are all therefore likely to miss much of the fine-scale segregation of species investigated in this work. We emphasise that the constrained method is only appropriate for calculating covariances when the frequency of the measurements is high and the modelled species is not significantly transported.

\subsection{Model setup}

The CiTTyCAT box model of atmospheric chemistry (Wild et al., 1996; Evans et al., 2000; Emmerson et al., 2004; Donovan et al., 2005; Real et al., 2007, 2008; Hewitt et al., 2009; Pugh et al., 2010) is used to apply this approach to the OP3 measurements. The model is run for the $12 \mathrm{~h}$ of daylight between 06:00 and 18:00 LT, and isoprene concentration is constrained by each of the $1 \mathrm{~s}$ measured concentrations, run for $10 \mathrm{~s}$. Gaps in the isoprene time series are filled by replicating a section of the immediately preceding data the same length as the gap. This is deemed acceptable as the characteristic spectrum of isoprene timescales is what is of interest in this analysis. If the $12 \mathrm{~h}$ data period contains gaps greater than $30 \mathrm{~min}$, data for that day are discarded. In total eleven days of suitable data are available for analysis for the first OP3 campaign (OP3-1) (April-May 2008).

The model is integrated on a time step of $1 \mathrm{~s}$, although the chemical solver itself uses intermediate time steps of a variable size (Brown et al., 1989). As the model has previously been optimised for the OP3 scenario by Pugh et al. (2010), the set-up described in that paper is largely retained, with the model being fed campaign average values of cloud cover (calculated using $j\left(\mathrm{O}^{1} \mathrm{D}\right)$ as a proxy) and temperature. Boundary layer height is set to $800 \mathrm{~m}$ throughout the run.

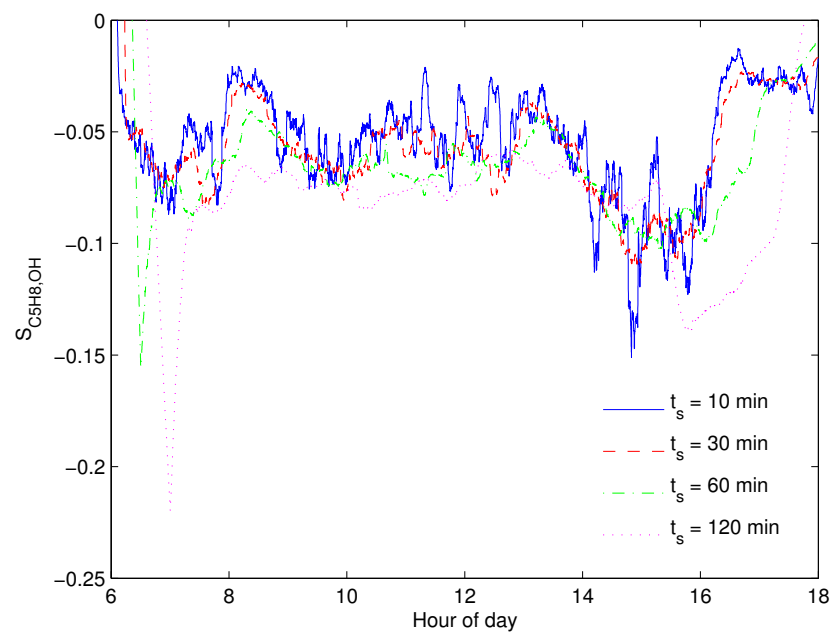

Fig. 3. Variation in $S_{\mathrm{C}_{5} \mathrm{H}_{8}, \mathrm{OH}}$ due to using $t_{s}=10,30,60$ and $120 \mathrm{~min}$. Carried out using OP3 isoprene measurements collected on $30 / 04 / 08$.

However it must be cautioned that LIDAR measurements of boundary layer height (Pearson et al., 2010) indicate that the BL is well-mixed throughout this $800 \mathrm{~m}$ range only between the hours of 10:00-18:00 LT. Therefore results before 10:00 LT will not be representative of the BL as a whole. Indeed the first hour must be discarded as spin-up time. We emphasise here that the BL height is only used for scaling the deposition rates of various intermediate species and the emission rate of NO, which both play some role in the calculation of the bulk terms $P$ and $O L$ (see Eq. 7). The influence of the chosen BL height on isoprene-OH covariances is indirect and minor.

Finally, the length of the time window, $t_{s}$, is of importance. When selecting $t_{s}$ it must be considered what elements should be classified as segregation and at what timescale variations start to reflect changing conditions (nonstationarities). For instance, if $t_{s}=1 \mathrm{~h}$, then variations in cloud cover and solar zenith angle may make a significant contribution to the variation. However, cloud cover and solar zenith angle changes are typically uniform across the boundary layer and therefore do not contribute to the spatial variation which is the subject of this work. In order to ensure that only factors such as canopy emission and BL turbulence dominate the variation, a shorter $t_{s}$ is required. To determine how short, the fast Fourier transform of measured $j\left(\mathrm{O}^{1} \mathrm{D}\right)$ (which implicitly incorporates both cloud cover and solar zenith angle changes) is computed (not shown); this indicates little variation on timescales shorter than $10 \mathrm{~min}$, suggesting $t_{s}=10 \mathrm{~min}$ would be sufficiently small to eliminate the effect of these lower frequency variations. Conveniently the BL turnover timescale, as calculated by Pugh et al. (2010), is also close to $10 \mathrm{~min}$, hence a time window of this length should be sufficient to allow sampling of the range of isoprene concentrations within the BL. Dlugi et al. (2010) find $t_{s}=10 \mathrm{~min}$ to 
be appropriate for their measurements of segregation intensity over a forest in Germany, by examining the covariances of $\mathrm{OH}$ and $\mathrm{j}\left(\mathrm{O}^{1} \mathrm{D}\right)$. As using $t_{s}=10 \mathrm{~min}$ also ignores the effects of slower frequency eddies, test calculations for $t_{s}=10$, 30, 60 and $120 \mathrm{~min}$ have been computed to give an indication of how the result is affected. Calculations were carried out using isoprene measurements collecting during the OP3 campaign on 30 April 2008. Figure 3 shows that the greatest deviations occur at the ends of the day, when changes in $\mathrm{j}\left(\mathrm{O}^{1} \mathrm{D}\right)$ are most rapid. Even when using $t_{s}=120 \mathrm{~min}$, which clearly incorporates significant non-stationarities, results during the middle period of the day were generally within a factor of two of those generated using $t_{s}=10 \mathrm{~min}$.

\section{Results and discussion}

\subsection{Case study of $\mathrm{OH}$-isoprene interactions above a German mixed forest (Dlugi et al., 2010)}

Dlugi et al. (2010) appear to have provided the only clear

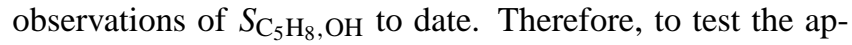
proach described above before making calculations for the OP3 campaign, the model was run for $4 \mathrm{~h}$ between 10:00 and 14:00 LT using an isoprene concentration time series produced by generating random numbers according to the distribution statistics specified in Dlugi et al. (2010). As only limited information about the physical and chemical characteristics of the Dlugi et al. (2010) measurement site were available, the model setup used for OP3 was retained with the following exceptions: The box was positioned at $50^{\circ} 54^{\prime} \mathrm{N}$, $6^{\circ} 24^{\prime} \mathrm{E}$, with NO emissions from the Yienger and Levy (1995) inventory for that location being used. The $\mathrm{j}\left(\mathrm{O}^{1} \mathrm{D}\right)$ measurements reported in Dlugi et al. (2010) were approximated by modifying the model cloud cover and the reported temperature measurements were also used. Initial concentrations for $\mathrm{O}_{3}$, NO, HCHO, MACR, MVK and HONO were set as reported in Dlugi et al. (2010) and Kleffmann et al. (2005), the latter measurements were for the same site but they were made a month earlier. As CiTTyCAT is currently unable to replicate the magnitude of daytime HONO formation that was observed at this site, the model is constrained to a constant HONO mixing ratio of $150 \mathrm{pptv}$, following the measurements of Kleffmann et al. (2005).

The result of this test is shown in Fig. 4. A reasonable agreement is achieved in terms of the timing and magnitude of the main peaks. The model does not capture all the variability in the observed data and tends to overestimate the depth of the troughs. However, as will be discussed in Sect. 4.3, the concentration of $\mathrm{OH}$ sinks other than isoprene has a damping effect on the magnitude of $S_{\mathrm{C}_{5} \mathrm{H}_{8}, \mathrm{OH}}$. At a site such as this in Western Europe, the concentrations of background species contributing to the $\mathrm{OH}$ sink may be quite high. Hence it is likely that our model will somewhat overestimate the magnitude of $S_{\mathrm{C}_{5} \mathrm{H}_{8}, \mathrm{OH}}$ in this case, without

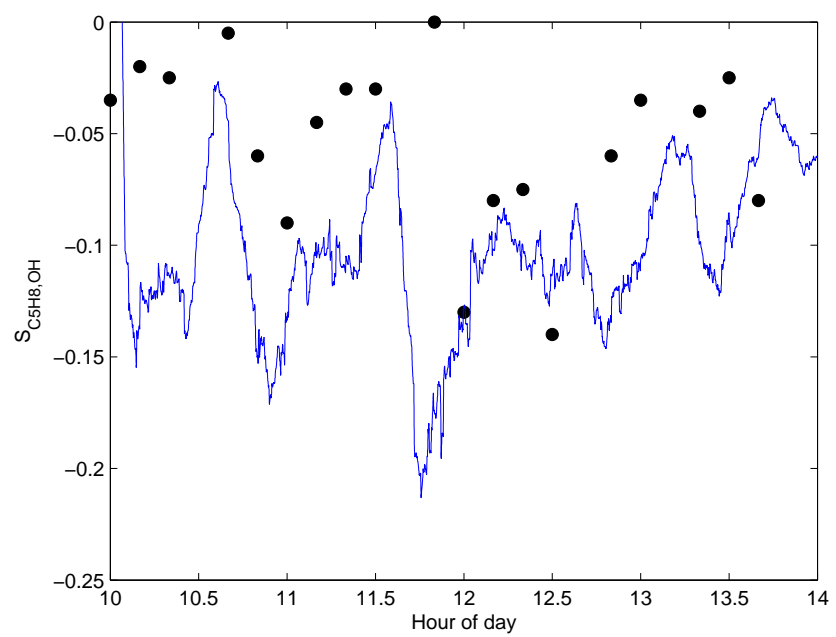

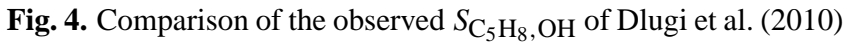
(black dots), with the model estimate using the approach described in this paper $\left(t_{s}=10 \mathrm{~min}\right)$ (blue line).

detailed information for the background species. When the

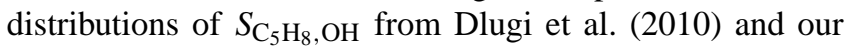
model are normalised to a mean of zero, a KolomogorovSmirnov test indicates that they are both from the same distribution at the $99 \%$ confidence level. This suggests that the variability of $S_{\mathrm{C}_{5} \mathrm{H}_{8}, \mathrm{OH}}$ is well represented by this modelling approach. Overall the agreement achieved is encouraging, suggesting that the model can effectively estimate $S_{\mathrm{C}_{5} \mathrm{H}_{8}, \mathrm{OH}}$ from the supplied isoprene data.

\subsection{Application to a tropical forest (OP3)}

Figure 5 shows the intensity of segregation calculated by the model for each day of available data for the OP3 campaign. $S_{\mathrm{C}_{5} \mathrm{H}_{8}, \mathrm{OH}}$ is much less negative than suggested in the studies of Butler et al. (2008) and Pugh et al. (2010) with a 10:00-18:00 LT mean of $S_{\mathrm{C}_{5} \mathrm{H}_{8}, \mathrm{OH}}=-0.054$ for $t_{s}=10 \mathrm{~min}$,

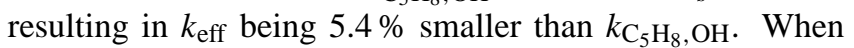
$t_{s}=60 \mathrm{~min}$, the 10:00-18:00 LT mean of $S_{\mathrm{C}_{5} \mathrm{H}_{8}, \mathrm{OH}}=-0.068$,

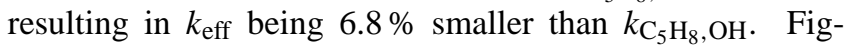

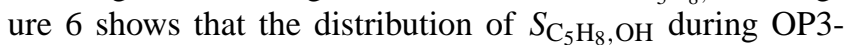
1 is strongly skewed with a tail towards the more negative values, with the median slightly less negative than the mean at $S_{\mathrm{C}_{5} \mathrm{H}_{8}, \mathrm{OH}}=-0.049$ for $t_{s}=10 \mathrm{~min}$. The 5 th and $95 \mathrm{th}$ percentiles are $S_{\mathrm{C}_{5} \mathrm{H}_{8}, \mathrm{OH}}=-0.104$ and $S_{\mathrm{C}_{5} \mathrm{H}_{8}, \mathrm{OH}}=-0.018$ respectively. A large variation in $S_{\mathrm{C}_{5} \mathrm{H}_{8}, \mathrm{OH}}$ is modelled over the course of each day, but $10 \mathrm{~min}$ average values never fall

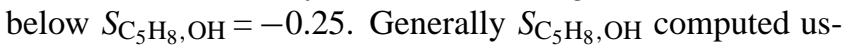
ing $t_{s}=60 \mathrm{~min}$ is more negative than for $t_{s}=10 \mathrm{~min}$, however the difference is not pronounced, with major deviations only occurring on a few occasions. This suggests that the most important component of $S_{\mathrm{C}_{5} \mathrm{H}_{8}, \mathrm{OH}}$ is that due to turbulence and emission variations which occur on timescales $<10 \mathrm{~min}$. 

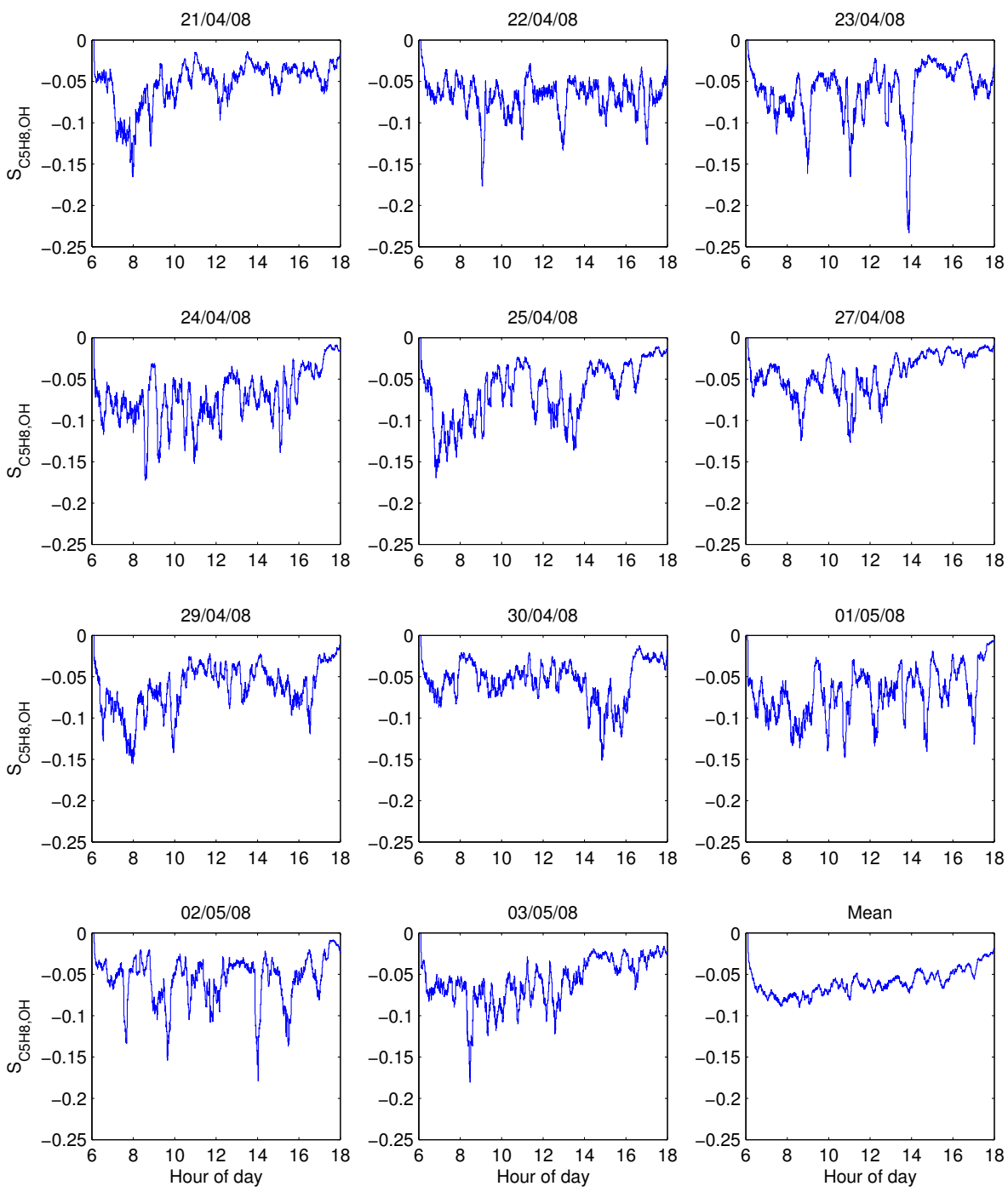

Fig. 5. Model calculated intensity of segregation for $t_{S}=10 \mathrm{~min}$, showing each day during OP3-1 and the overall mean. Note that results before 10:00 LT are not representative of the boundary layer as a whole.

Figure 7 shows that $S_{\mathrm{C}_{5} \mathrm{H}_{8} \text {, OH }}$ is not strongly correlated with either the standard deviation $(\sigma)$ or the mean $(\mu)$ of the isoprene concentration. However the combination of these two statistics, $\sigma_{\mathrm{C}_{5} \mathrm{H}_{8}} / \mu_{\mathrm{C}_{5} \mathrm{H}_{8}}$, i.e. the relative standard deviation, correlates strongly with the intensity of segregation. This is likely due to the rate of increase of the overall reaction rate of isoprene and $\mathrm{OH}, d R_{\mathrm{C}_{5} \mathrm{H}_{8}, \mathrm{OH}} /\left\langle C_{5} H_{8}\right\rangle$, decreasing with increasing isoprene concentration. Therefore a given $\sigma_{\mathrm{C}_{5} \mathrm{H}_{8}}$ will produce a greater range of $R_{\mathrm{C}_{5} \mathrm{H}_{8}, \mathrm{OH}}$ over $t_{s}$, when $\mu_{\mathrm{C}_{5} \mathrm{H}_{8}}$ is low. This indicator becomes less accurate as $S_{\mathrm{C}_{5} \mathrm{H}_{8}, \mathrm{OH}}$ becomes more negative; we can find no simple explanation for this increase in scatter. It could be due to a combination of the skewness and kurtosis of the isoprene distribution, combined with the $\mathrm{OH}$ production rate and the size of the non-isoprene $\mathrm{OH}$ sink. One feature of the plots in Fig. 7 is that, rather than a quasi-random scatter of data, the data points tend to arrange themselves in trajectories. This is most obvious with some of the outliers. This behaviour is a result of using running means over the input data, meaning that each point is influenced to some extent by the last, and should not be interpreted mechanistically.

The calculation of $S_{\mathrm{C}_{5} \mathrm{H}_{8}}$, OH presented in this section is specific to the OP3 measurement site, as the relative deviation of the isoprene concentration will depend strongly upon the strength of the isoprene emission flux and upon the behaviour of the factors that make this flux heterogeneous in time and space, e.g. species distribution, canopy venting, small-scale turbulence. This could lead to a large

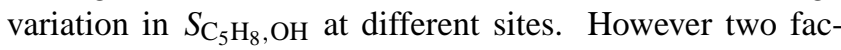
tors are worth noting here. The first is that the measurements of Dlugi et al. (2010) for a forest in Germany and the mod-

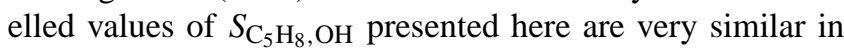




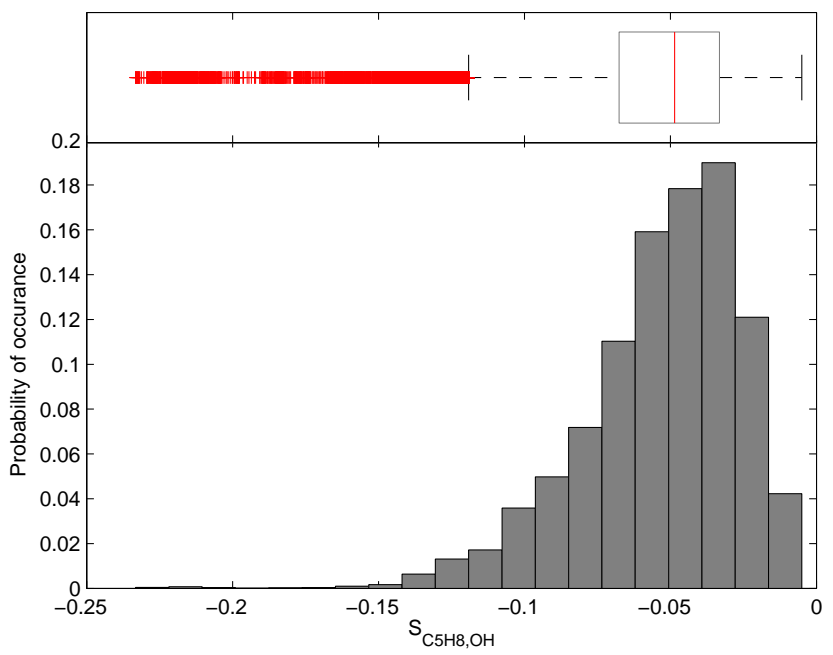

Fig. 6. Lower panel: Histogram showing probability of occurrence of $S_{\mathrm{C}_{5} \mathrm{H}_{8}, \mathrm{OH}}$ based upon all 10:00-18:00 LT calculations for the OP3-1 campaign. Upper panel: Box and whisker plot showing median (red line) and upper and lower quartiles (box). The upper (lower) whisker encompasses the region within 3 times the region between the upper (lower) quartile and the mean. Outliers are shown by a red cross.

magnitude despite their differing locations. The second is that OP3 observed relatively small isoprene emissions compared to studies over the Amazon rainforest (Langford et al., 2010). At higher isoprene emissions the relative deviation will be smaller for a similar amplitude of variation; from Fig. 7 this implies a less negative value of $S_{\mathrm{C}_{5} \mathrm{H}_{8}, \mathrm{OH}}$.

\subsection{Sensitivity}

Figure 7 demonstrates that the most important variables for $S_{\mathrm{C}_{5} \mathrm{H}_{8} \text {,OH }}$ identified by this study are the magnitude and standard deviation of the isoprene concentration. To test how much the underlying photochemical characteristics of the

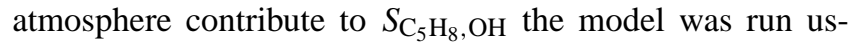
ing a normally-distributed, pseudo-randomly generated sequence of isoprene mixing ratios with a mean of $2 \mathrm{ppbv}$ and a range of $0-4 \mathrm{ppbv}$. The result, shown by the heavy lines in Fig. 8, reveals a relative minimum in the absolute magnitude of $S_{\mathrm{C}_{5} \mathrm{H}_{8}, \mathrm{OH}}$ at $\sim 11: 00 \mathrm{LT}$, coincident with the onset of precipitation, and hence a reduction in the non-isoprene $\mathrm{OH}$ sink due to the removal of highly soluble species such as peroxides. This clearly demonstrates that the magnitude of the non-isoprene $\mathrm{OH}$ sink can have an impact on the magnitude of $S_{\mathrm{C}_{5} \mathrm{H}_{8}, \mathrm{OH}}$. In effect the additional sink dampens the size of $\mathrm{OH}^{\prime}$ caused by a given $\mathrm{C}_{5} \mathrm{H}_{8}{ }^{\prime}$. In these simulations

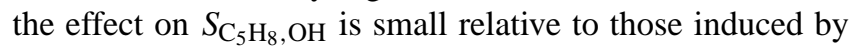
changes in the isoprene distribution (Fig. 5), as isoprene and its oxidation products dominated the OH sink during OP3. However, in a more polluted environment, correctly accounting for other $\mathrm{OH}$ sinks would become very important, al- though of course, in such an environment, the importance of $S_{\mathrm{C}_{5} \mathrm{H}_{8}, \mathrm{OH}}$ would be proportionally smaller.

Plotting [OH] against $S_{\mathrm{C}_{5} \mathrm{H}_{8} \text {, OH }}$ for the OP3 scenario suggests a correlation between the two variables (not shown). However, this is not real; when the random isoprene time series is used, no correlation is seen with $[\mathrm{OH}]$. Therefore the apparent correlation in the OP3 scenario must be a result of the shape of the diurnal $[\mathrm{OH}]$ signal being similar to that of isoprene, since both are ultimately controlled by solar radiation. Furthermore, running the model using a constant photolysis rate, and hence constant photolytic $\mathrm{OH}$ production, leads to deviation in $S_{\mathrm{C}_{5} \mathrm{H}_{8} \text {, OH }}$ only at the extreme ends of the day compared to a run with normal photolysis. Hence $[\mathrm{OH}]$ cannot be determined to have any significant predictive

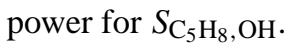

Several recent papers have suggested that the tropospheric oxidation of isoprene might include a hitherto unconsidered $\mathrm{OH}$ formation mechanism, especially under conditions of low $\mathrm{NO}_{\mathrm{x}}$ concentrations (Lelieveld et al., 2008; Peeters et al., 2009). For the purposes of this work, the most important factor in such an $\mathrm{OH}$ production mechanism is the time between initial isoprene oxidation and $\mathrm{OH}$ formation. If the extra $\mathrm{OH}$ was formed very rapidly then it could decrease $S_{\mathrm{C}_{5} \mathrm{H}_{8}, \mathrm{OH}}$, as the $\mathrm{OH}$ loss caused by isoprene oxidation would immediately be balanced to some extent by an $\mathrm{OH}$ source. Running the model with the reaction of $\mathrm{C}_{5} \mathrm{H}_{8}+\mathrm{OH}$ modified to directly produce one molecule of $\mathrm{OH}$ for each molecule of isoprene oxidised, as in Pugh et al. (2010), results in $S_{\mathrm{C}_{5} \mathrm{H}_{8}, \mathrm{OH}}=0$. However there is no known chemical scheme that could describe such a production mechanism.

If additional $\mathrm{OH}$ is produced further down the isoprene oxidation chain, then the additional $\mathrm{OH}$ source is unlikely to be co-located with isoprene, instead being spread much more homogeneously across the boundary layer. To date, only Peeters et al. (2009) have proposed a detailed mechanism for how extra $\mathrm{OH}$ of the quantity apparently required by models might be formed. They point out a number of places in the oxidation scheme where possible extra $\mathrm{OH}$ yields may occur. By far the most important route is by the photolysis of hydroperoxy-aldehyde compounds formed as a secondary oxidation product of isoprene. Peeters et al. (2009) estimate the photolysis frequency for these compounds to be $J=3 \times 10^{-4} \mathrm{~s}^{-1}$, with a quantum yield of $100 \%$, giving a lifetime of approximately $1 \mathrm{~h}$. This suggests that $\mathrm{OH}$ formation via this route will not be preferentially co-located with isoprene, as air parcels are highly unlikely to remain undiluted over this time period. In this case, as it has already been demonstrated that the $\mathrm{OH}$ concentration cannot be shown to have any direct effect on $S_{\mathrm{C}_{5} \mathrm{H}_{8}, \mathrm{OH}}, \mathrm{OH}$ recycling on the timescale of an hour in the isoprene oxidation scheme is not expected to make any difference to $S_{\mathrm{C}_{5} \mathrm{H}_{8}, \mathrm{OH}}$. To test this, the model was run for data from 30 April 2008 with an additional $\mathrm{OH}$ source one step further down the isoprene oxidation chain. The result yields virtually no change in $S_{\mathrm{C}_{5} \mathrm{H}_{8}, \mathrm{OH}}$ (not shown). 

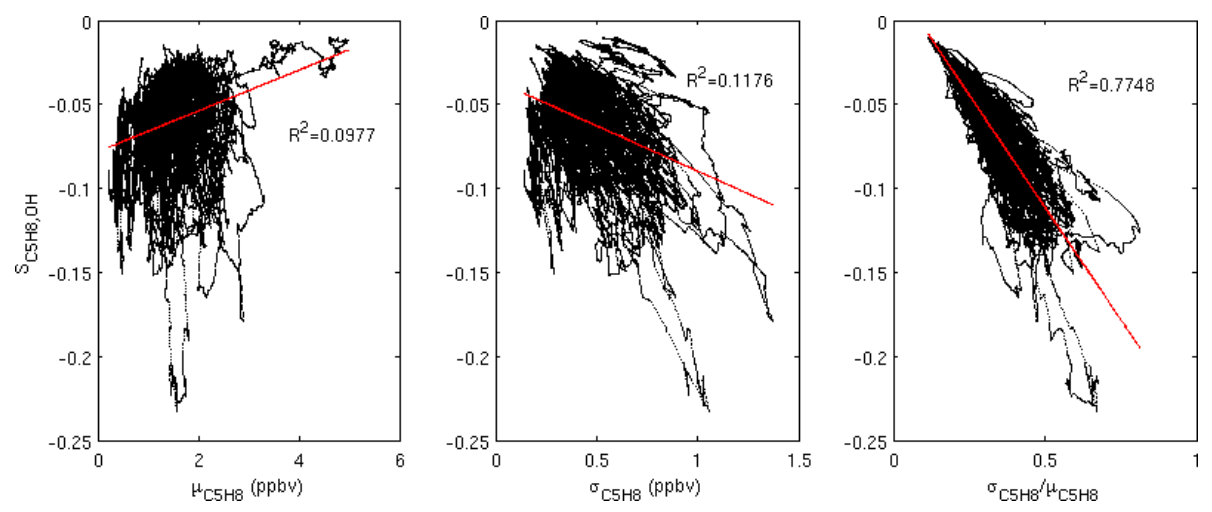

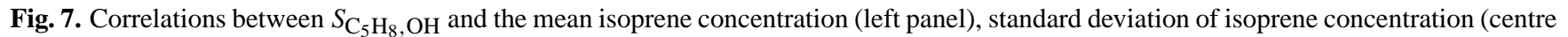
panel), and relative deviation (right panel). Values between 10:00-16:00 LT are used and $t_{s}=10 \mathrm{~min}$.

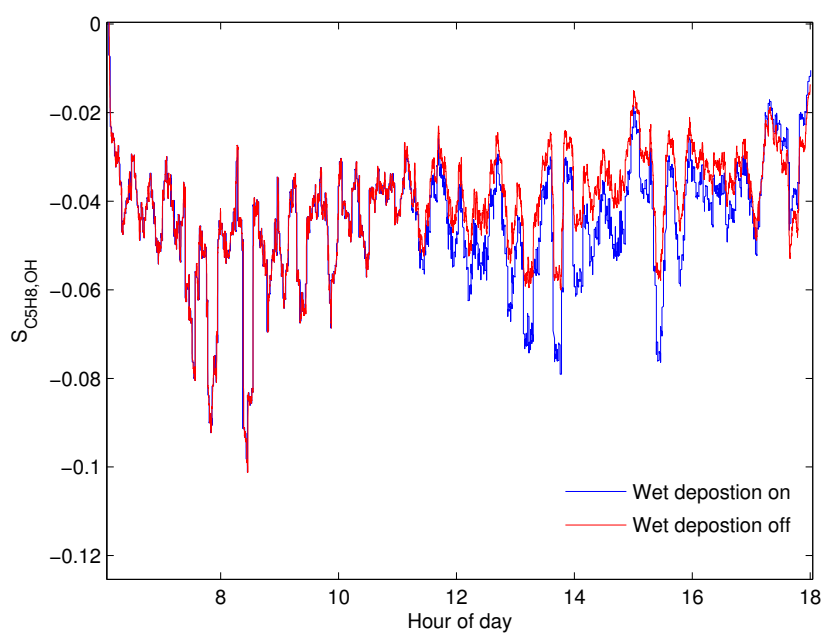

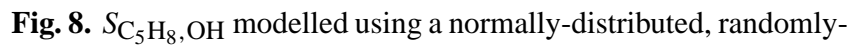
generated isoprene time-series. The red line shows a run in which wet deposition was turned off.

Another issue of potential importance is the inhomogeneous distribution within the boundary layer of species other than isoprene. Krol et al. (2000) found that heterogeneous emission of NO, in addition to that of isoprene, led to a decreased magnitude of $\mathrm{S}_{\mathrm{VOC}, \mathrm{OH}}$; an $\mathrm{OH}$ gradient formed as a result of the NO fluctuations, counteracting the effect of the VOC and $\mathrm{OH}$ segregation. NO is likely to be heterogeneously distributed as its principal source at the OP3 measurement site is biogenic below-canopy emissions. Therefore a spatial and temporal variation in both its original source, and its release from the canopy, is likely. No high temporal resolution measurement of NO concentration were made during OP3, but $1 \mathrm{~Hz}$ measurements of $\mathrm{NO}_{2}$ concentration made at $75 \mathrm{~m}$ on the measurement tower, show variations in $\mathrm{NO}_{2}$ concentration with an amplitude of the same magnitude as the mean concentration, on a timescale of less than $1 \mathrm{~min}$. As $\mathrm{NO}$ and $\mathrm{NO}_{2}$ are quickly inter-converted in the daytime boundary layer, this suggests a heterogeneous distribution of $\mathrm{NO}$ within the boundary layer.

To test the effect of heterogeneous NO concentrations, three further runs were carried out constrained to a randomlygenerated normally distributed isoprene time-series. The first of these runs, N1, was constrained to a NO mixing ratio of $50 \mathrm{pptv}$ if isoprene mixing ratios were greater than $2.5 \mathrm{ppbv}$, $10 \mathrm{pptv}$ if isoprene mixing ratios were less than $1.5 \mathrm{ppbv}$, and $30 \mathrm{pptv}$ if isoprene mixing ratios were between 1.5 and 2.5 ppbv. This produced an effect where high NO concentrations were more typically co-located with high isoprene concentrations; an effect that may well occur if coupling of the canopy to the BL is the primary reason for heterogeneous concentration distributions. The second of these runs, N2, was identical except a NO mixing ratio of $10 \mathrm{pptv}$ was used if isoprene mixing ratios were greater than $2.5 \mathrm{ppbv}$, and a NO mixing ratio of $50 \mathrm{pptv}$ was used if isoprene mixing ratios were less than $1.5 \mathrm{ppbv}$, resulting in a scenario where high NO concentrations were typically anti-correlated with high isoprene concentrations. Finally N3 was constrained to a randomly-generated NO time-series that was entirely independent of isoprene.

Figure 9 shows the results for runs N1, N2 and N3, compared to the standard run for that day. Run N1 shows a substantial decrease in segregation, with much less negative $S_{\mathrm{C}_{5} \mathrm{H}_{8}, \mathrm{OH}}$, as found by Krol et al. (2000). Indeed, at the ends of the day, when $\mathrm{OH}$ production via photolysis is relatively small compared to production via the reaction of peroxy radicals with $\mathrm{NO}, S_{\mathrm{C}_{5} \mathrm{H}_{8} \text {, OH }}$ can even become positive as the effect on $[\mathrm{OH}]$ caused by increased $[\mathrm{NO}]$ dominates over the effect caused by decreased isoprene.

Run N2 has the opposite effect, showing that NO concentrations anti-located with isoprene concentrations could yield significantly more negative values of $S_{\mathrm{C}_{5} \mathrm{H}_{8}, \mathrm{OH}}$. However, this $\mathrm{N} 2$ scenario appears unlikely in reality as the dominant source of NO during OP3 was attributed to soil emissions (e.g. Pugh et al., 2010). Although the soil source of NO and canopy source of isoprene are distinct, an anti-correlation of 


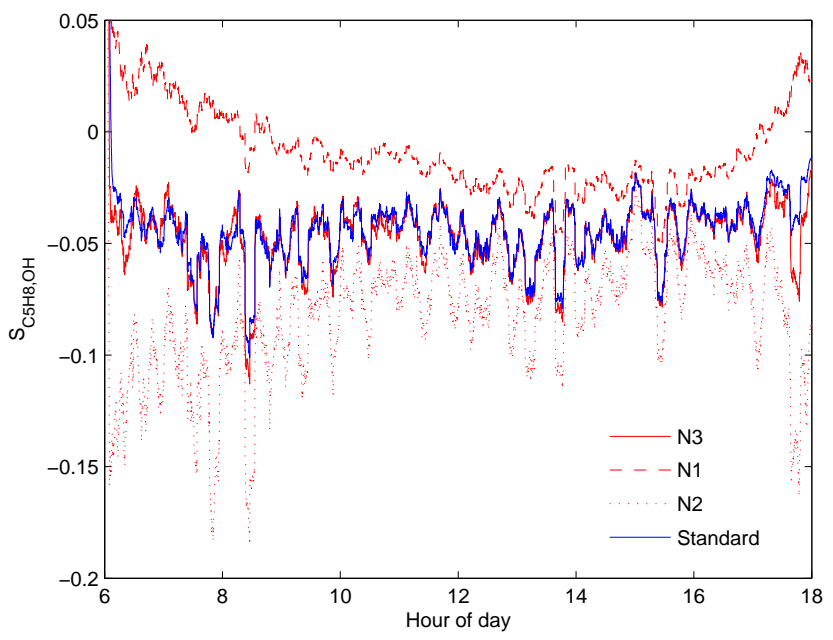

Fig. 9. The effect of heterogeneous NO concentrations correlated with those of isoprene (N1, red dashes), anti-correlated with those of isoprene (N2, red dots), and showing no correlation with isoprene (N3, red line), compared with a standard run (blue line) for a randomly-generated isoprene time-series.

these species is unlikely, since NO emissions from the soil must transit past the isoprene-rich canopy to reach the BL. Aircraft measurements indicate that $\left[\mathrm{NO}_{\mathrm{x}}\right]$ in the free troposphere is much lower than that in the BL (Hewitt et al., 2009), ruling out a free tropospheric $\mathrm{NO}_{\mathrm{x}}$ source which could cause an anti-correlation. Therefore, we deduce that the most likely scenario is either $\mathrm{N} 1$, or that the distributions of $\mathrm{NO}$ and isoprene in the BL will simply be different and uncorrelated. Run N3 demonstrates that if any heterogeneities in the NO concentration are independent of those in the isoprene con-

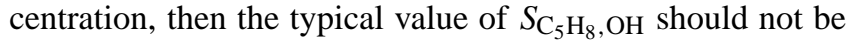
affected.

Overall the sensitivity tests indicate that our estimation of $S_{\mathrm{C}_{5} \mathrm{H}_{8}, \mathrm{OH}}$ is likely to represent an upper limit. An increase in $O L$ due to unaccounted-for species would tend to decrease $S_{\mathrm{C}_{5} \mathrm{H}_{8}, \mathrm{OH}}$, as would plausible covariances of isoprene with other trace species which could influence $P$. For instance, the covariance of isoprene and water vapour is directly analogous to the covariance of isoprene and NO described above.

\section{Conclusions}

An approach has been described to model the intensity of segregation of isoprene and $\mathrm{OH}$ using high temporal resolution isoprene concentration data. The approach shows good agreement when compared with the only observations of isoprene and $\mathrm{OH}$ segregation available in the literature. When the method is applied to measurements made over the southeast Asian tropical rainforest during the OP3 campaign, an intensity of segregation typically less negative than -0.15 is estimated. This is much less negative than the -0.5 re- quired by global and box models of atmospheric chemistry to reconcile their $\mathrm{OH}$ and isoprene concentrations with measurements. We emphasise that the results of this study are limited to the segregation of isoprene and $\mathrm{OH}$ alone, and not the segregation of any other species with $\mathrm{OH}$.

The model-estimated intensity of segregation for the OP3 rainforest scenario described in this paper is subject to many unconstrained uncertainties; in particular the distribution of $\mathrm{OH}$ sources and non-isoprene $\mathrm{OH}$ sinks. However, the nature of the processes involved is such that these uncertainties would tend the result towards less negative values of intensity of segregation. The result appears robust to potential $\mathrm{OH}$ recycling, unless such recycling happens virtually instantaneously following initial isoprene oxidation. Given that rapid isoprene concentration measurements have been made during several other field campaigns, it is suggested that the approach described here might be applied to estimate the intensity of segregation in those regions.

Both Butler et al. (2008) and Pugh et al. (2010) have demonstrated that additional $\mathrm{OH}$ recycling in the isoprene oxidation scheme can only improve model fits to measured $\mathrm{OH}$ concentrations at the expense of the fit to measured isoprene concentrations/fluxes. In order to attain an acceptable fit to both $\mathrm{OH}$ and isoprene concentrations a reduction in $k_{\mathrm{C}_{5} \mathrm{H}_{8}, \mathrm{OH}}$ was required. However this work shows that, at least for the rainforest conditions observed during the OP3 campaigns in Malaysia, segregation of isoprene and $\mathrm{OH}$ can only be responsible for a minor fraction of the rate constant reduction required to resolve the measurement-model discrepancy; hence either another justification for this $k_{\mathrm{C}_{5} \mathrm{H}_{8}, \mathrm{OH}}$ reduction must be made or an alternative solution found.

In the light of the results presented here, it is suggested that the highest temporal resolution measurements for isoprene available are utilised in constrained modelling studies of atmospheric chemistry in areas where isoprene dominates the $\mathrm{OH}$ sink. If high temporal resolution measurements of other species are co-located with the isoprene measurement (i.e. sufficiently close that they are very likely measuring within the same air parcel) then it may prove advantageous to use these also.

\section{Appendix A}

The timescale for the $\mathrm{OH}$ concentration to reach a new steady state following a perturbation in the isoprene mixing ratio from 2 to 3 ppbv (assuming no other $\mathrm{OH}$ sinks), is found by integrating the volume average conservation equation:

$\frac{\partial\langle\mathrm{OH}\rangle}{\partial t}=P-k_{\mathrm{C}_{5} \mathrm{H}_{8}, \mathrm{OH}}\langle\mathrm{OH}\rangle\left\langle\mathrm{C}_{5} \mathrm{H}_{8}\right\rangle$

where,

$P=k_{\mathrm{O}^{1} \mathrm{D}, \mathrm{H}_{2} \mathrm{O}}\left\langle\mathrm{O}^{1} \mathrm{D}\right\rangle\left\langle\mathrm{H}_{2} \mathrm{O}\right\rangle+k_{\mathrm{NO}, \mathrm{HO}_{2}}\langle\mathrm{NO}\rangle\left\langle\mathrm{HO}_{2}\right\rangle$ 


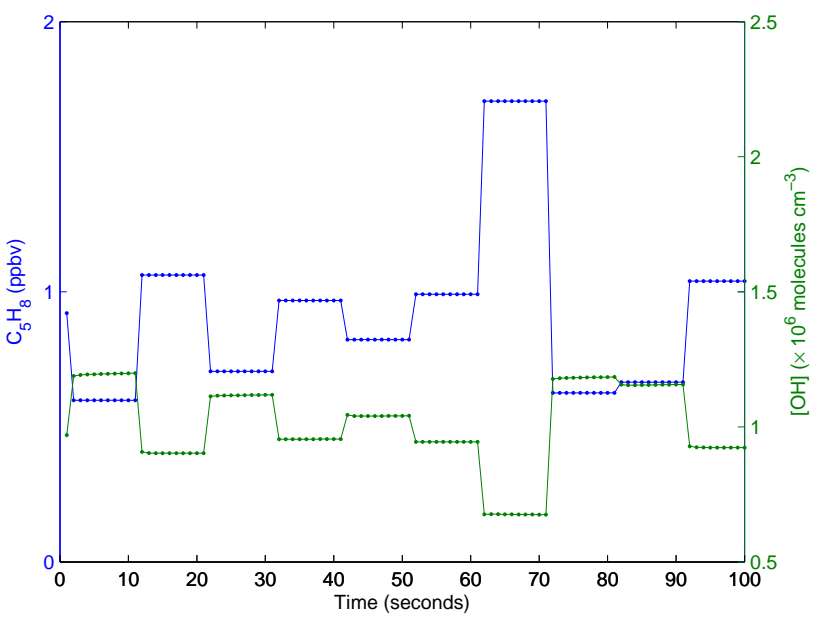

Fig. A1. Response of modelled $[\mathrm{OH}]$ to a change in the supplied $\mathrm{C}_{5} \mathrm{H}_{8}$. Each model time-point is marked by a dot.

to yield

$t=\left[\frac{-1}{k_{\mathrm{C}_{5} \mathrm{H}_{8}, \mathrm{OH}}\left\langle\mathrm{C}_{5} \mathrm{H}_{8}\right\rangle} \ln \left|P-k_{\mathrm{C}_{5} \mathrm{H}_{8}, \mathrm{OH}}\langle\mathrm{OH}\rangle\left\langle\mathrm{C}_{5} \mathrm{H}_{8}\right\rangle\right|\right]_{\langle\mathrm{OH}\rangle_{0}}^{\langle\mathrm{OH}\rangle_{t}}$

where $\langle\mathrm{OH}\rangle_{0}$ is the $\mathrm{OH}$ concentration at $t=0$ and $\langle\mathrm{OH}\rangle_{t}$ is the $\mathrm{OH}$ concentration at time $t$, when the system is in steady state. At steady state $\partial\langle\mathrm{OH}\rangle / \partial t=0$, therefore,

$P=k_{\mathrm{C}_{5} \mathrm{H}_{8}, \mathrm{OH}}\langle\mathrm{OH}\rangle\left\langle\mathrm{C}_{5} \mathrm{H}_{8}\right\rangle$

Hence the $\langle\mathrm{OH}\rangle_{t}$ limit of Eq. A3 is zero. When a $P=3.0 \times 10^{6}$ moleculescm $\mathrm{cm}^{-3} \mathrm{~s}^{-1}$ is used, $t=3 \mathrm{~s}$. This value of $P$ is based upon midday typical midday values of the components of Eq. (A2) during the OP3 campaign (Hewitt et al., 2010). As the approach to steady state is exponential in nature, the majority of this change in $[\mathrm{OH}]$ due to a perturbation in $\left[\mathrm{C}_{5} \mathrm{H}_{8}\right]$ will occur within $1 \mathrm{~s}$. This is demonstrated in Fig. A1 which shows an extract of the model time-series for $\mathrm{C}_{5} \mathrm{H}_{8}$ (blue) and $\mathrm{OH}$ (green). Each mark represents a model timestep of one second. It is clear that the $\mathrm{OH}$ response to a change in $\mathrm{C}_{5} \mathrm{H}_{8}$ concentration occurs nearly entirely within the first timestep following the change.

Acknowledgements. The authors wish to thank A. Jarvis for stimulating the discussion that led to this work and for helpful comments, P. Di Carlo for sharing his $\mathrm{NO}_{2}$ data, and P. H. Haynes (DAMTP, Cambridge) and K. Ashworth for their kind assistance with the analysis. They also wish to acknowledge the advice of two anonymous reviewers, whose comments greatly improved the clarity of the manuscript. We thank the Malaysian and Sabah Governments for their permission to conduct research in Malaysia; the Malaysian Meteorological Department for access to the Bukit Atur Global Atmosphere Watch station; Waidi Sinun of Yayasan Sabah and his staff, Glen Reynolds of the Royal Society's South East Asian Rainforest Research Programme and his staff, and Nick Chappell and Brian Davison of Lancaster University for logistical support at the Danum Valley Field Centre. The work was funded by the Natural Environment Research Council Grants NE/D002117/1 and NE/E011179/1. This is paper number 508 of the Royal Society's South East Asian Rainforest Research Programme.

Edited by: A. B. Guenther

\section{References}

Brown, P., Byrne, G., and Hindmarsh, A.: VODE -A Variablecoefficient ODE solver, Siam J. Sci. Stat. Comp.,, 10, 10381051, 1989.

Butler, T. M., Taraborrelli, D., Brühl, C., Fischer, H., Harder, H., Martinez, M., Williams, J., Lawrence, M. G., and Lelieveld, J.: Improved simulation of isoprene oxidation chemistry with the ECHAM5/MESSy chemistry-climate model: lessons from the GABRIEL airborne field campaign, Atmos. Chem. Phys., 8, 4529-4546, doi:10.5194/acp-8-4529-2008, 2008.

Carslaw, N., Creasey, D., Harrison, D., Heard, D., Hunter, M., Jacobs, P., Jenkin, M., Lee, J., Lewis, A., Pilling, M., Saunders, S., and Seakins, $\mathrm{P}$.: $\mathrm{OH}$ and $\mathrm{HO}_{2}$ radical chemistry in a forested region of north-western Greece, Atmos. Environ., 35, 4725-4737, 2001.

Dlugi, R., Berger, M., Zelger, M., Hofzumahaus, A., Siese, M., Holland, F., Wisthaler, A., Grabmer, W., Hansel, A., Koppmann, R., Kramm, G., Möllmann-Coers, M., and Knaps, A.: Turbulent exchange and segregation of $\mathrm{HO}_{\mathrm{x}}$ radicals and volatile organic compounds above a deciduous forest, Atmos. Chem. Phys., 10, 6215-6235, doi:10.5194/acp-10-6215-2010, 2010.

Donovan, R., Hope, E., Owen, S., Mackenzie, A., and Hewitt, C.: Development and Application of an Urban Tree Air Quality Score for Photochemical Pollution Episodes Using the Birmingham, United Kingdom, Area as a Case Study, Environ. Sci. Technol., 39, 6730-6738, 2005.

Emmerson, K. M., MacKenzie, A. R., Owen, S. M., Evans, M. J., and Shallcross, D. E.: A Lagrangian model with simple primary and secondary aerosol scheme 1: comparison with UK PM10 data, Atmos. Chem. Phys., 4, 2161-2170, doi:10.5194/acp-42161-2004, 2004.

Emmerson, K., Carslaw, N., Carpenter, L., Heard, D., Lee, J., and Pilling, M.: Urban atmospheric chemistry during the PUMA campaign 1: Comparison of modelled $\mathrm{OH}$ and $\mathrm{HO}_{2}$ concentrations with measurements, J. Atmos. Chem., 52, 143-164, doi:10.1007/s10874-005-1322-3, 2005.

Emmerson, K. M., Carslaw, N., Carslaw, D. C., Lee, J. D., McFiggans, G., Bloss, W. J., Gravestock, T., Heard, D. E., Hopkins, J., Ingham, T., Pilling, M. J., Smith, S. C., Jacob, M., and Monks, P. S.: Free radical modelling studies during the UK TORCH Campaign in Summer 2003, Atmos. Chem. Phys., 7, 167-181, doi:10.5194/acp-7-167-2007, 2007.

Evans, M., Shallcross, D., Law, K., Wild, J., Simmonds, P., Spain, T., Berrisford, P., Methven, J., Lewis, A., McQuaid, J., Pilling, M., Bandy, B., Penkett, S., and Pyle, J.: Evaluation of a Lagrangian box model using field measurements from EASE (Eastern Atlantic Summer Experiment) 1996, Atmos. Environ., 34, 3843-3863, 2000.

Granier, C., Petron, G., Muller, J., and Brasseur, G.: The impact of natural and anthropogenic hydrocarbons on the tropospheric budget of carbon monoxide, Atmos. Environ., 34, 5255-5270, 6th Scientific Conference of the International Global Atmospheric 
Chemistry Project (IGAC), Bologna, Italy, 13-17 September, 1999, 2000.

Guenther, A., Hewitt, C., Erickson, D., Fall, R., Geron, C., Graedel, T., Harley, P., Klinger, L., Lerdau, M., McKay, W., Pierce, T., Scholes, B., Steinbrecher, R., Tallamraju, R., Taylor, J., and Zimmerman, P.: A global model of natural volatile organic compound emissions, J. Geophys. Res., 100, 8873-8892, 1995.

Hayward, S., Hewitt, C., Sartin, J., and Owen, S.: Performance characteristics and applications of a proton transfer reaction-mass spectrometer for measuring volatile organic compounds in ambient air, Environ. Sci. Tech., 36, 1554-1560, doi:10.1021/es0102181, 2002.

Helfter, C., Phillips, G., Coyle, M., Di, Marco, C., Langford, B., Whitehead, J., Dorsey, J., Gallagher, M., Sei, E., Fowler, D., and Nemitz, E.: Momentum and heat exchange above South East Asian rainforest in complex terrain, Atmos. Chem. Phys. Discuss., in preparation, 2010.

Hewitt, C. N., MacKenzie, A. R., Di Carlo, P., Di Marco, C. F., Dorsey, J. R., Evans, M., Fowler, D., Gallagher, M. W., Hopkins, J. R., Jones, C. E., Langford, B., Lee, J. D., Lewis, A. C., Lim, S. F., McQuaid, J., Misztal, P., Moller, S. J., Monks, P. S., Nemitz, E., Oram, D. E., Owen, S. M., Phillips, G. J., Pugh, T. A. M., Pyle, J. A., Reeves, C. E., Ryder, J., Siong, J., Skiba, U., and Stewart, D. J.: Nitrogen management is essential to prevent tropical oil palm plantations from causing ground-level ozone pollution, P. Natl. Acad. Sci. USA, 106, 18447-18451, doi:10.1073/pnas.0907541106, 2009.

Hewitt, C. N., Lee, J. D., MacKenzie, A. R., Barkley, M. P., Carslaw, N., Carver, G. D., Chappell, N. A., Coe, H., Collier, C., Commane, R., Davies, F., Davison, B., DiCarlo, P., Di Marco, C. F., Dorsey, J. R., Edwards, P. M., Evans, M. J., Fowler, D., Furneaux, K. L., Gallagher, M., Guenther, A., Heard, D. E., Helfter, C., Hopkins, J., Ingham, T., Irwin, M., Jones, C., Karunaharan, A., Langford, B., Lewis, A. C., Lim, S. F., MacDonald, S. M., Mahajan, A. S., Malpass, S., McFiggans, G., Mills, G., Misztal, P., Moller, S., Monks, P. S., Nemitz, E., Nicolas-Perea, V., Oetjen, H., Oram, D. E., Palmer, P. I., Phillips, G. J., Pike, R., Plane, J. M. C., Pugh, T., Pyle, J. A., Reeves, C. E., Robinson, N. H., Stewart, D., Stone, D., Whalley, L. K., and Yang, X.: Corrigendum to "Overview: oxidant and particle photochemical processes above a south-east Asian tropical rainforest (the OP3 project): introduction, rationale, location characteristics and tools" published in Atmos. Chem. Phys., 10, 169199, 2010, Atmos. Chem. Phys., 10, 563-563, doi:10.5194/acp10-563-2010, 2010.

Hofzumahaus, A., Rohrer, F., Lu, K., Bohn, B., Brauers, T., Chang, C.-C., Fuchs, H., Holland, F., Kita, K., Kondo, Y., Li, X., Lou, S., Shao, M., Zeng, L., Wahner, A., and Zhang, Y.: Amplified Trace Gas Removal in the Troposphere, Science, 324, 17021704, doi:10.1126/science.116456, 2009.

IUPAC: Evaluated kinetic data, http://www.iupac-kinetic.ch.cam. ac.uk/, last access: 19th March 2009, 2009.

Jöckel, P., Tost, H., Pozzer, A., Brhl, C., Buchholz, J., Ganzeveld, L., Hoor, P., Kerkweg, A., Lawrence, M. G., Sander, R., Steil, B., Stiller, G., Tanarhte, M., Taraborrelli, D., van Aardenne, J., and Lelieveld, J.: The atmospheric chemistry general circulation model ECHAM5/MESSy1: consistent simulation of ozone from the surface to the mesosphere, Atmos. Chem. Phys., 6, 50675104, doi:10.5194/acp-6-5067-2006, 2006.
Kanaya, Y., Cao, R., Kato, S., Miyakawa, Y., Kajii, Y., Tanimoto, H., Yokouchi, Y., Mochida, M., Kawamura, K., and Akimoto, H.: Chemistry of $\mathrm{OH}$ and $\mathrm{HO}_{2}$ radicals observed at Rishiri Island, Japan, in September 2003: Missing daytime sink of $\mathrm{HO}_{2}$ and positive nighttime correlations with monoterpenes, J. Geophys. Res., 112, D11308, doi:10.1029/2006JD007987, 2007.

Kanaya, Y., Pochanart, P., Liu, Y., Li, J., Tanimoto, H., Kato, S., Suthawaree, J., Inomata, S., Taketani, F., Okuzawa, K., Kawamura, K., Akimoto, H., and Wang, Z. F.: Rates and regimes of photochemical ozone production over Central East China in June 2006: a box model analysis using comprehensive measurements of ozone precursors, Atmos. Chem. Phys., 9, 7711-7723, doi:10.5194/acp-9-7711-2009, 2009.

Kleffmann, J., Gavriloaiei, T., Hofzumahaus, A., Holland, F., Koppmann, R., Rupp, L., Schlosser, E., Siese, M., and Wahner, A.: Daytime formation of nitrous acid: A major source of $\mathrm{OH}$ radicals in a forest, Geophys. Res. Lett., 32, L05818, doi:10.1029/2005GL022524, 2005.

Krol, M., Molemaker, M., and Vilà Guerau de Arellano, J.: Effects of turbulence and heterogeneous emissions on photochemically active species in the convective boundary layer, J. Geophys. Res., 105, 6871-6884, 2000.

Kubistin, D., Harder, H., Martinez, M., Rudolf, M., Sander, R., Bozem, H., Eerdekens, G., Fischer, H., Gurk, C., Klüpfel, T., Königstedt, R., Parchatka, U., Schiller, C. L., Stickler, A., Taraborrelli, D., Williams, J., and Lelieveld, J.: Hydroxyl radicals in the tropical troposphere over the Suriname rainforest: comparison of measurements with the box model MECCA, Atmos. Chem. Phys., 10, 9705-9728, doi:10.5194/acp-10-97052010, 2010.

Langford, B., Misztal, P. K., Nemitz, E., Davison, B., Helfter, C., Pugh, T. A. M., MacKenzie, A. R., Lim, S. F., and Hewitt, C. N.: Fluxes and concentrations of volatile organic compounds from a South-East Asian tropical rainforest, Atmos. Chem. Phys., 10, 8391-8412, doi:10.5194/acp-10-8391-2010, doi:10.5194/acp-10-8391-2010, 2010.

Lawrence, M., Crutzen, P., Rasch, P., Eaton, B., and Mahowald, N.: A model for studies of tropospheric photochemistry: Description, global distributions, and evaluation, J. Geophys. Res., 104, 26245-26277, 1999.

Lelieveld, J., Peters, W., Dentener, F., and Krol, M.: Stability of tropospheric hydroxyl chemistry, J. Geophys. Res., 107, doi:10.1029/2002JD002272, 2002.

Lelieveld, J., Butler, T. M., Crowley, J. N., Dillon, T. J., Fischer, H., Ganzeveld, L., Harder, H., Lawrence, M. G., Martinez, M., Taraborrelli, D., and Williams, J.: Atmospheric oxidation capacity sustained by a tropical forest, Nature, 452, 737-740, doi:10.1038/nature06870, 2008.

Martinez, M., Harder, H., Kubistin, D., Rudolf, M., Bozem, H., Eerdekens, G., Fischer, H., Klpfel, T., Gurk, C., Knigstedt, R., Parchatka, U., Schiller, C. L., Stickler, A., Williams, J., and Lelieveld, J.: Hydroxyl radicals in the tropical troposphere over the Suriname rainforest: airborne measurements, Atmos. Chem. Phys., 10, 3759-3773, doi:10.5194/acp-10-3759-2010, 2010.

McMillen, R.: An eddy-correlation technique with extended applicability to non-simple terrain, Bound.-Lay. Meteorol., 43, 231245, 1988.

Patton, E., Davis, K., Barth, M., and Sullivan, P.: Decaying scalars emitted by a forest canopy: A numerical study, Bound.-Lay. Me- 
teorol., 100, 91-129, 2001.

Pearson, G., Davies, F., and Collier, C.: Remote sensing of the tropical rain forest boundary layer using pulsed Doppler lidar, Atmos. Chem. Phys., 10, 5891-5901, doi:10.5194/acp-10-58912010, 2010.

Peeters, J., Nguyen, T. L., and Vereecken, L.: $\mathrm{HO}_{\mathrm{x}}$ radical regeneration in the oxidation of isoprene, Phys. Chem. Chem. Phys., 11, 5935-5939, doi:10.1039/b908511d, 2009.

Poisson, N., Kanakidou, M., and Crutzen, P.: Impact of nonmethane hydrocarbons on tropospheric chemistry and the oxidizing power of the global troposphere: 3-dimensional modelling results, J. Atmos. Chem., 36, 157-230, 2000.

Powell, D. and Elderkin, C.: Investigation of application of Taylor's hypothesis to atmospheric boundary-layer turbulence, J. Atmos. Sci., 31, 990-1002, 1974.

Pugh, T. A. M., MacKenzie, A. R., Hewitt, C. N., Langford, B., Edwards, P. M., Furneaux, K. L., Heard, D. E., Hopkins, J. R., Jones, C. E., Karunaharan, A., Lee, J., Mills, G., Misztal, P., Moller, S., Monks, P. S., and Whalley, L. K.: Simulating atmospheric composition over a South-East Asian tropical rainforest: performance of a chemistry box model, Atmos. Chem. Phys., 10, 279-298, doi:10.5194/acp-10-279-2010, 2010.

Real, E., Law, K. S., Weinzierl, B., Fiebig, M., Petzold, A., Wild, O., Methven, J., Arnold, S., Stohl, A., Huntrieser, H., Roiger, A., Schlager, H., Stewart, D., Avery, M., Sachse, G., Browell, E., Ferrare, R., and Blake, D.: Processes influencing ozone levels in Alaskan forest fire plumes during longrange transport over the North Atlantic, J. Geophys. Res., 112, doi:10.1029/2006JD007576, 2007.

Real, E., Law, K. S., Schlager, H., Roiger, A., Huntrieser, H., Methven, J., Cain, M., Holloway, J., Neuman, J. A., Ryerson, T., Flocke, F., de Gouw, J., Atlas, E., Donnelly, S., and Parrish, D.: Lagrangian analysis of low altitude anthropogenic plume processing across the North Atlantic, Atmos. Chem. Phys., 8, $7737-$ 7754, doi:10.5194/acp-8-7737-2008, 2008.

Ren, X., Olson, J. R., Crawford, J. H., Brune, W. H., Mao, J., Long, R. B., Chen, Z., Chen, G., Avery, M. A., Sachse, G. W., Barrick, J. D., Diskin, G. S., Huey, L. G., Fried, A., Cohen, R. C., Heikes, B., Wennberg, P. O., Singh, H. B., Blake, D. R., and Shetter, R. E.: $\mathrm{HO}_{\mathrm{x}}$ chemistry during INTEX-A 2004: Observation, model calculation, and comparison with previous studies, J. Geophys. Res., 113, D05310, doi:10.1029/2007JD009166, 2008.

Schumann, U.: Large-eddy simulation of turbulent-diffusion with chemical-reactions in the convective boundary-layer, Atmos. Environ., 23, 1713-1727, 1989.

Spirig, C., Neftel, A., Ammann, C., Dommen, J., Grabmer, W., Thielmann, A., Schaub, A., Beauchamp, J., Wisthaler, A., and Hansel, A.: Eddy covariance flux measurements of biogenic VOCs during ECHO 2003 using proton transfer reaction mass spectrometry, Atmos. Chem. Phys., 5, 465-481, doi:10.5194/acp-5-465-2005, 2005.
Sykes, R., Parker, S., Henn, D., and Lewellen, W.: Turbulent mixing with chemical-reaction in the planetary boundary-layer, J. Appl. Meteorol., 33, 825-834, 1994.

Tan, D., Faloona, I., Simpas, J., Brune, W., Olson, J., Crawford, J., Avery, M., Sachse, G., Vay, S., Sandholm, S., Guan, H., Vaughn, T., Mastromarino, J., Heikes, B., Snow, J., Podolske, J., and Singh, $\mathrm{H} .: \mathrm{OH}$ and $\mathrm{HO}_{2}$ in the tropical Pacific: Results from PEM-Tropics B, J. Geophys. Res., 106, 32667-32681, 2001.

Vilà Guerau de Arellano, J., Duynkerke, P., and Zeller, K.: Atmospheric surface-layer similarity theory applied to chemically reactive species, J. Geophys. Res. Atm., 100, 1397-1408, 1995.

Vinuesa, J. and Vilà Guerau de Arellano, J.: Fluxes and (co)variances of reacting scalars in the convective boundary layer, Tellus B, 55, 935-949, 2003.

Vinuesa, J. and Vilà Guerau de Arellano, J.: Introducing effective reaction rates to account for the inefficient mixing of the convective boundary layer, Atmos. Environ., 39, 445-461, doi:10.1016/j.atmosenv.2004.10.003, 2005.

Vinuesa, J.-F. and Porte-Agel, F.: Dynamic models for the subgridscale mixing of reactants in atmospheric turbulent reacting flows, J. Atmos. Sci., 65, 1692-1699, doi:10.1175/2007JAS2392.1, 2008.

von Kuhlmann, R., Lawrence, M., Poschl, U., and Crutzen, P.: Sensitivities in global scale modeling of isoprene, Atmos. Chem. Phys., 4, 1-17, 2004.

Wang, Y., Jacob, D., and Logan, J.: Global simulation of tropospheric $\mathrm{O}_{3}-\mathrm{NO}_{\mathrm{x}}$-hydrocarbon chemistry 3. Origin of tropospheric ozone and effects of nonmethane hydrocarbons, J. Geophys. Res., 103, 10757-10767, 1998.

Whalley, L. K., Edwards, P. M., Furneaux, K. L., Goddard, A., Ingham, T., Evans, M. J., Stone, D., Hopkins, J. R., Jones, C. E., Karunaharan, A., Lee, J. D., Lewis, A. C., Monks, P. S., Moller, S. J., and Heard, D. E.: Quantifying the magnitude of a missing hydroxyl radical source in a tropical rainforest, Atmos. Chem. Phys. Discuss., 11, 5785-5809, doi:10.5194/acpd11-5785-2011, 2011.

Wild, O., Law, K., McKenna, D., Bandy, B., Penkett, S., and Pyle, J.: Photochemical trajectory modeling studies of the North Atlantic region during August 1993, J. Geophys. Res., 101, 29269 $29288,1996$.

Yienger, J. and Levy, H.: Empirical model of global soil biogenic $\mathrm{NO}_{\mathrm{X}}$ emissions, J. Geophys. Res., 100, 11447-11464, 1995. 